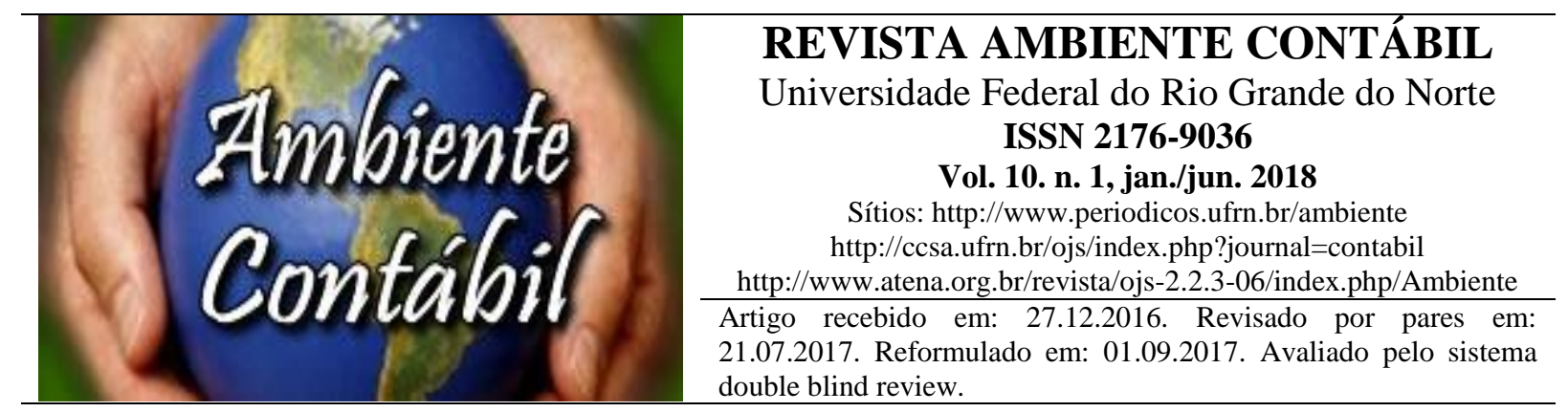

\title{
ÍNDICE DE SUSTENTABILIDADE EMPRESARIAL: UMA ANÁLISE ACERCA DA EVIDENCIAÇÃO DO PASSIVO AMBIENTAL
}

\section{BUSINESS SUSTAINABILITY INDEX: AN ANALYSIS OF EVIDENCE OF ENVIRONMENTAL LIABILITY \\ ÍNDICE DE SOSTENIBILIDAD SOCIAL: UM ANÁLISIS DE LOS PASIVOS AMBIENTALES DIVULGACIÓN}

Autores

Mário de Carvalho Filho

Mestrando em Controladoria pela Universidade Federal Rural de Pernambuco. Analista Ministerial - Ciências Contábeis Ministério Público de Pernambuco. Endereço: Rua Dom Manoel de Medeiros, s/n, Dois Irmãos - CEP: 52.171-900, Recife/PE - Brasil. Telefone: (81) $3320-5451$.

Identificadores (ID): Lattes: http://lattes.cnpq.br/0541617539204292 E-mail: mcf2508@hotmail.com

Márcio Sampaio Pimentel

Doutor em Fitotecnia pela Universidade Federal Rural do Rio de Janeiro (UFRRJ). Professor Adjunto do Departamento de Administração da Universidade Federal Rural de Pernambuco (UFRPE). Endereço: Rua Dom Manoel de Medeiros, s/n, Dois Irmãos - CEP: 52.171-900, Recife/PE - Brasil. Telefone: (81) 3320-5451. Identificadores (ID): Lattes: http://lattes.cnpq.br/1944948543483633 E-mail: marciospimentel@gmail.com

Rafaela Maria José Bertino Mestranda em Controladoria pela Universidade Federal Rural de Pernambuco. Endereço: Rua Dom Manoel de Medeiros, s/n, Dois Irmãos - CEP: 52.171-900, Recife/PE - Brasil.

Telefone: (81) 3320-5451 Identificadores (ID): Lattes: http://lattes.cnpq.br/2757203405794580

E-mail: bertino.rafaela@gmail.com 
Mário de Carvalho Filho, Márcio Sampaio Pimentel, Rafaela Maria José Bertino e Anália Regina de Lima Oliveira

\author{
Anália Regina de Lima Oliveira \\ Mestranda em Controladoria pela Universidade Federal Rural de Pernambuco \\ Rua Dom Manoel de Medeiros, s/n, Dois Irmãos - CEP: 52.171-900, Recife/PE - Brasil. \\ Telefone: (81) 3320-5451 \\ Identificadores (ID): \\ Lattes: http://lattes.cnpq.br/8203555818058114 \\ E-mail: annalialima@gmail.com
}

\begin{abstract}
RESUMO
O objetivo deste artigo é descrever como as empresas participantes do Índice de Sustentabilidade Empresarial (ISE) da BM\&F BOVESPA, declararam-se em relação a seus passivos ambientais durante o período de 2012-2015. A pergunta norteadora consiste em: Como as empresas participantes do ISE da BM\&F BOVESPA se auto declararam em relação a seus passivos ambientais no período 2012-2015. A partir da prospecção dos relatórios de 67 empresas que participaram do ISE neste período, e que tratou, especificamente, sobre a sua situação em relação a eventuais passivos ambientais, foi possível perceber que $43 \%$ das empresas que responderam ao questionário nos anos 2012-2015 declararam não possuir passivos ambientais. Outrossim, apenas 9\% declararam possuir passivos ambientais, provisionaram recursos para o seu saneamento, divulgaram a existência destes passivos nos relatórios pertinentes e estabeleceram metas para o saneamento integral de seus passivos comprovados por meio de documentos que somente a BM\&F BOVESPA tem acesso - o que demostra um baixo nível de evidenciação ambiental por parte das empresas do ISE, fato este que prejudica os investidores e outros usuários das demonstrações financeiras.
\end{abstract}

Palavras-chave: Evidenciação Ambiental. Passivo Ambiental. Índice de Sustentabilidade Empresarial.

\begin{abstract}
The objective of this paper was to describe how the companies listed on BM \& F Bovespa's Corporate Sustainability Index (CSI) have declared themselves in relation to their environmental liabilities between the years of 2012-2015, using for this, 67 reports of companies that were listed, and had discussed specifically about its situation in relation to possible environmental liabilities. The results indicate that $43 \%$ of the companies declared not to have environmental liabilities, while only $9 \%$ declared that besides having environmental liabilities, provides resources for their sanitation, disclose their liabilities in the reports and set targets for sanitation liabilities (varying between 3, 5 and 10 years). These answers demonstrate the commitment with sustainable practices by the companies, increasingly charged by society and, particularly, by investors. However, such evidence is only accessible by BM \& F BOVESPA, thus demonstrating, a low level of environmental disclosure by companies that compose the CSI.
\end{abstract}

Keywords: Environmental disclosure. Environmental liabilities. Corporate Sustainability Index (CSI).

\title{
RESUMEN
}

El objetivo del artículo es describir cómo las empresas que participan del Índice de Sostenibilidad Empresarial (ISE) de la BM\&F BOVESPA se auto declaran con relación a sus

Revista Ambiente Contábil - ISSN 2176-9036 - UFRN - Natal-RN. v. 10. n. 1, p. 104 - 120, jan./jun. 2018. 
Mário de Carvalho Filho, Márcio Sampaio Pimentel, Rafaela Maria José Bertino e Anália Regina de Lima Oliveira

pasivos ambientales entre los años 2012-2015, utilizándose para eso, 67 reportes de las empresas que participan del ISE en el periodo, y que trató, específicamente, sobre su situación con relación a eventuales pasivos ambientales. Los resultados indican que el $43 \%$ de las empresas que contestaron el cuestionario declararon no poseer pasivos ambientales, al cabo que solamente $9 \%$ declararon que además de poseer pasivos ambientales, provisionaron recursos para su saneamiento, divulgan sus pasivos en los reportes y establecen metas para el saneamiento integral de los pasivos (variando entre 3, 5 y 10 años). Estas respuestas demuestran el involucramiento de las empresas con prácticas sostenibles, cada vez más exigidos por la sociedad y particularmente por los inversionistas. Sin embargo, esas comprobaciones son posibles solamente por la BM\&F BOVESPA que tiene acceso, demuestran así, bajo nivel de evidenciación ambiental por parte de las empresas que componen el ISE.

Palabras-clave: Evidenciación Ambiental. Pasivo Ambiental. Índice de Sostenibilidad Empresarial.

\section{INTRODUÇÃO}

O impacto causado pelas atividades econômicas das organizações tem prejudicado demasiadamente o meio ambiente no qual vivemos. A sociedade, o governo e o mercado estão mais exigentes em relação ao comprometimento das empresas com o desenvolvimento sustentável. Isto contribuiu para que as companhias passassem a divulgar com mais transparência os seus processos produtivos alinhados com a preservação do meio ambiente. Desta forma, os consumidores passaram a dar preferência para estas empresas, tornando a responsabilidade social das organizações uma vantagem competitiva (HAHN, REZENDE \& NOSSA, 2010; ROSA et al., 2011).

Assim, para atender aos investidores preocupados com o desenvolvimento sustentável da economia, começaram a surgir indicadores de mercado que ofereciam, além de dados financeiros, informações mais precisas em relação aos modelos de gestão das empresas e os seus respectivos comprometimentos com os fatores éticos, ambientais e sociais. O Dow Jones Sustainability Indexes (DJSI), surgido em 1999, foi o primeiro índice a considerar estes fatores. Em seguida, surgiram o FTSE4Good em Londres, o JSE em Joanesburgo e, em 2005, foi lançado na BM\&F BOVESPA o Índice de Sustentabilidade Ambiental (ISE) (BM\&F BOVESPA, 2016).

O ISE foi criado para mostrar o desempenho de mercado de uma carteira formada por empresas que adotam os princípios da gestão sustentável. A seleção das empresas participantes é realizada mediante o preenchimento voluntário de um questionário, que demonstra o comprometimento da organização com questões relativas à sustentabilidade. Assim, é possível mostrar quais são as atitudes da empresa em relação a aspectos ambientais como, por exemplo, a evidenciação de passivos ambientais.

Inicialmente, é interessante esclarecer que o reconhecimento de um passivo ambiental não significa que a empresa cometeu uma ação que agrediu o meio ambiente e resultou em uma multa advinda do prejuízo ambiental causado. Filho, Bruni e Gomes (2013) esclarecem que o surgimento de um passivo ambiental pode se dar por atitudes voltadas à sustentabilidade, como a execução de medidas preventivas, para reduzir o impacto no meio ambiente.

Ribeiro e Lisboa (2000), por sua vez, ensinam que o reconhecimento do passivo ambiental pela empresa é importante para a correta demonstração da situação econômico-

Revista Ambiente Contábil - ISSN 2176-9036 - UFRN - Natal-RN. v. 10. n. 1, p. 104 - 120, jan./jun. 2018. 
Mário de Carvalho Filho, Márcio Sampaio Pimentel, Rafaela Maria José Bertino e Anália Regina de Lima Oliveira

financeira da instituição, evitando que em uma reorganização societária, as obrigações de reparação de danos ao meio ambiente causem prejuízo ao comprador.

Rover et al. (2012) explicam que, no Brasil, não existe a obrigatoriedade de evidenciação ambiental. Desta forma, o disclosure ambiental é predominantemente voluntário, o que provoca algumas falhas como falta de qualidade das demonstrações; presença, apenas, de informações positivas nos relatórios e; ausência de padronização na evidenciação, impedindo a comparação entre as empresas.

Neste sentido, a evidenciação voluntária é influenciada por alguns fatores determinantes, tal qual Murcia et al. (2008), ao refletirem a divulgação voluntária ambiental nas Demonstrações Financeiras Padronizadas, identificaram como fatores determinantes da evidenciação ambiental voluntária o tamanho da empresa, a existência de auditoria e a participação no ISE.

Levando estes fatos em consideração, elaboramos a seguinte questão com vistas ao desenvolvimento desta pesquisa: Como as empresas participantes do ISE da BM\&F BOVESPA se auto declararam em relação a seus passivos ambientais nos anos de 2012 2015? Na tentativa de responder a esta pergunta, o objetivo principal deste artigo consiste em descrever como as empresas participantes do ISE da BM\&F BOVESPA se auto declararam em relação a seus passivos ambientais no período compreendido entre 2012 e 2015.

Acredita-se que esta pesquisa é relevante na medida em que auxilia os investidores e usuários das demonstrações financeiras na tomada de decisão, fornecendo dados acerca do nível de evidenciação dos passivos ambientais nas empresas que compõem o ISE da BM\&F BOVESPA. Este artigo está organizado da seguinte forma: além desta introdução, apresentase o referencial teórico, no qual são expostos os aspectos teóricos sobre o tema tratado, a metodologia da pesquisa para a consecução do objetivo proposto, análise e discussão dos resultados. Por fim, nas considerações finais, apresentamos sugestões para pesquisas futuras, além de referências bibliográficas.

\section{REFERENCIAL TEÓRICO}

Para fundamentar essa investigação serão abordados nessa seção, conhecimentos sobre passivos ambientais e Índice de Sustentabilidade Empresarial (ISE). No primeiro eixo temático serão abordados aspectos conceituais acerca de passivos ambientais (RIBEIRO e LISBOA, 2000), assim como a importância de sua evidenciação para os diversos atores interessados no tema (COSTA e MARION, 2007; LINS e SILVA, 2009), já no segundo serão descritas algumas características do ISE (SILVA et al. 2009) e o impacto para a imagem das empresas que participam do índice (FLORES et al. 2013).

\subsection{PASSIVOS AMBIENTAIS}

Conhecer os conceitos de passivo, passivo contingente e provisão, é algo fundamental para o entendimento acerca do passivo ambiental. É oportuno lembrar que o CPC 25Provisões, Passivos Contingentes e Ativos Contingentes, através da deliberação CVM n ${ }^{\circ}$ 594/09, regulamenta a sua evidenciação para as companhias abertas. Na visão de Almeida e Batista (2016), mesmo existindo dispositivos normativos específicos, ainda há incertezas que envolvem provisões e passivos contingentes. Para os autores a discricionariedade aumenta a complexidade sobre as estimativas e divulgação dos passivos, causando reflexos nas demonstrações financeiras das empresas.

Tais reflexos alcançam principalmente as empresas inovadoras que, independentemente de terem sido forçadas por leis ou pressão social, passaram a reconhecer

Revista Ambiente Contábil - ISSN 2176-9036 - UFRN - Natal-RN. v. 10. n. 1, p. 104 - 120, jan./jun. 2018. 
Mário de Carvalho Filho, Márcio Sampaio Pimentel, Rafaela Maria José Bertino e Anália Regina de Lima Oliveira

em seus balanços patrimoniais os respectivos passivos ambientais. Neste sentido, Bertoli e Ribeiro (2006) explicam que a inclusão de informações ambientais nos demonstrativos financeiros reflete, para os usuários das demonstrações, a preocupação das empresas com aspectos sociais e sua posição em relação ao meio ambiente. Essas condutas, na visão das autoras, refletirão na imagem da organização e, respectivamente, em sua situação patrimonial.

Ferreira, Bufoni e Muniz (2007, p.3), ao pesquisarem acerca da utilização do modelo ISAR/UNCTAD da ONU, trouxeram a definição de passivo ambiental segundo este grupo da organização. Para eles "passivos ambientais são obrigações relacionadas com os custos ambientais incorridos por uma empresa e que atendem aos critérios de reconhecimento de passivo". No entendimento de Sperandio, Trindade e Favero (2005), o passivo ambiental representa a reponsabilidade da empresa com aspectos ambientais, como por exemplo danos causados ao meio ambiente. Por fim, para Ribeiro e Lisboa (2000, p. 1):

\begin{abstract}
Passivo ambiental representa o sacrifício de benefícios econômicos que serão realizados para a preservação, recuperação e proteção do meio ambiente de forma a permitir a compatibilidade entre o desenvolvimento econômico e o meio ecológico ou em decorrência de uma conduta inadequada em relação às questões ambientais (RIBEIRO; LISBOA, 2000, p. 1).
\end{abstract}

A partir da conceituação exposta por esses autores - Ribeiro e Lisboa (2000), Sperandio, Trindade e Favero (2005) e Filho, Bruni e Gomes (2013) - em relação aos passivos ambientais, depreende-se que não se deve considerar o passivo ambiental como um sinônimo de acidente ambiental. Eles alertam que, muitas vezes, o reconhecimento do passivo ambiental decorre de uma atitude preventiva para se evitar um dano ao meio ambiente e, desta conduta, surgem efeitos econômicos e financeiros que geram um passivo social.

A divulgação de informações financeiras com baixa qualidade para os steakholders influencia negativamente na tomada de decisão dos usuários. Para aqueles que desejam investir na empresa, o prejuízo consiste em não ser possível avaliar o real desempenho financeiro desta, pois os demonstrativos contábeis não representam fielmente a situação financeira da organização (BERTOLI; RIBEIRO, 2006).

A relevância da evidenciação ambiental influencia de distintas formas cada um dos atores interessados nos impactos ambientas resultantes das atividades empresariais. Costa e Marion (2007), ao pesquisarem sobre a uniformidade entre as informações ambientais presentes nos relatórios das empresas de papel e celulose no site da BM\&F BOVESPA e em seus sites oficiais, destacaram que as informações ambientais são de interesse de diversos tipos de usuário, tais como: fornecedores, bancos, investidores, governo, sociedade, dentre outros. Na visão de Lins e Silva (2009), a evidenciação ambiental representa um relevante meio de comunicação acerca do desempenho da empresa e de seus interessados, sendo estes: acionistas, credores, órgão de supervisão e controle, governo e empregados. Ainda segundo os mesmos autores, a evidenciação ambiental possui o efeito de reduzir a assimetria de informações entre as organizações e suas partes interessadas.

A preocupação da sociedade com o meio ambiente aumentou nas últimas décadas, mais pessoas estão interessadas em saber qual é o impacto ambiental dos processos produtivos de produtos e serviços oferecidos pelas empresas. Assim sendo, as informações ambientais ganharam relevância para a sociedade. Costa e Marion (2007) explicam que, a sociedade passou a exigir dessas empresas uma maior responsabilidade ambiental. Já Nogueira e Angotti (2011), ao identificarem a reação do mercado de capitais frente à divulgação de vazamentos de petróleo, demonstraram o interesse da sociedade pela evidenciação ambiental. Em ambas as pesquisas, os autores também destacaram o

Revista Ambiente Contábil - ISSN 2176-9036 - UFRN - Natal-RN. v. 10. n. 1, p. 104 - 120, jan./jun. 2018. 
Mário de Carvalho Filho, Márcio Sampaio Pimentel, Rafaela Maria José Bertino e Anália Regina de Lima Oliveira

desdobramento das exigências sociais para o mercado, que passa a escolher aquelas organizações preocupadas com o meio ambiente.

Fernandes (2013) expõe o interesse dos investidores na evidenciação ambiental, ao investigar se a degradação ambiental resultante de diversos setores influencia na decisão de compra e de venda dos acionistas. Interessa destacar, que esse movimento de compra e venda de ações reflete diretamente no valor da empresa, tornando-a um dos atores mais interessados na divulgação de suas informações ambientais. Para Flores et al. (2013), os investidores dão preferência às empresas socialmente responsáveis e sustentáveis quando do momento de investirem seus recursos, na medida em que acreditam que essas organizações estão mais preparadas para enfrentar riscos econômicos, sociais e ambientais. Fernandes (2013b), ao verificar os fatores que influenciam o disclosure ambiental das empresas brasileiras listadas na BM\&F BOVESPA no período de 2006 a 2010, afirma que as empresas brasileiras têm adotado a evidenciação ambiental como forma de alavancar o seu valor de mercado e aumentar a sua credibilidade em relação aos stakeholders, logo elas obtêm financiamentos, novos mercados e maiores retornos financeiros.

É oportuno destacar que, como o interesse das organizações em evidenciar as suas informações ambientais possui como principal objetivo o aumento do valor de mercado da empresa, muitas companhias utilizam como estratégia de marketing a evidenciação apenas de informações que impactem positivamente na imagem da instituição. Deste modo, terminam evidenciando aspectos menos relevantes para os usuários (MUSSOI; BELLEN, 2010 \& MIRANDA; MALAQUIAS, 2013). Jacobs, Singhal, Subramanian (2010) investigaram a relação entre o valor de mercado da empresa e o seu desempenho ambiental, e concluíram que os impactos de informações ambientais negativas no preço das ações atingem às organizações de maneiras distintas, de acordo com o setor de atuação de cada uma delas. Neste sentido, percebe-se que a relevância da informação ambiental pode variar de acordo com o setor de atuação da corporação.

Não apenas a sociedade, as empresas e os acionistas atribuem relevância para a evidenciação ambiental. O governo, por meio de seus órgãos fiscalizadores, participa deste grupo de interessados nas informações ambientais de duas formas distintas: concedendo-lhes licenças e certificados para a realização de suas atividades, assim como na aplicação de multas ambientais. Estas multas podem comprometer o desempenho financeiro das instituições, dependendo do tipo de infração (COSTA, MARION, 2007). Na visão de Bertoli e Ribeiro (2006), a ausência da evidenciação ambiental pode influenciar negativamente na avaliação de uma operação de compra da empresa, prejudicando a oportunidade da realização de investimento na organização. $O$ que pode ocasionar futuras disputas judiciais fundamentadas na ausência de passivos ambientais existentes na organização. Para Rosa et al. (2011), a evidenciação ambiental representa o meio de comunicação entre as organizações e a sociedade.

\section{2 ÍNDICE DE SUSTENTABILIDADE EMPRESARIAL (ISE)}

O Índice de Sustentabilidade Empresarial (ISE) foi criado em 2005 com o financiamento inicial da International Finance Corporation (IFC), braço financeiro do Banco Mundial. Seu desenvolvimento ficou por conta do Centro de Estudos em Sustentabilidade (GVces) da Escola de Administração de Empresas da Fundação Getúlio Vargas (FGV) (BOVESPA, 2016). Segundo Dias e Barros (2008), a criação do ISE procura atender a uma tendência por parte dos investidores em procurarem empresas sustentáveis e rentáveis para aplicar os seus recursos. Eles acreditam que estas empresas estão mais preparadas para

Revista Ambiente Contábil - ISSN 2176-9036 - UFRN - Natal-RN. v. 10. n. 1, p. 104 - 120, jan./jun. 2018 
Mário de Carvalho Filho, Márcio Sampaio Pimentel, Rafaela Maria José Bertino e Anália Regina de Lima Oliveira

enfrentar os riscos econômicos, sociais e ambientais apresentados por uma competição global entre as organizações.

Neste sentido, Knoepfel (2001) declara que, cada vez mais os investidores estão diversificando suas carteiras de investimento na direção do conceito de sustentabilidade corporativa. Segundo os autores, as empresas sustentáveis, à longo prazo, apresentam resultados mais previsíveis, o que significa menos surpresas negativas. Portanto, os investidores procurarão as empresas líderes em sustentabilidade, não para um desempenho desmedido temporário, mas para um crescimento confiável de longo prazo.

Para a BM\&F BOVESPA (2016), o objetivo do ISE consiste em mostrar o desempenho médio de uma carteira teórica das ações de empresas (no máximo 40) que possuem reconhecido comprometimento com a responsabilidade social e práticas empresariais sustentáveis. Para Teixeira, Nossa e Funchal (2001), o índice funciona como um benchmark de empresas que se destacam em boas práticas sustentáveis e que são comprometidas com a Responsabilidade Social Corporativa (RSC). De acordo com Silva et al. (2009), a base do ISE é o resultado da união de práticas de governança corporativa com o conceito de Triple Botton Line (TBL). Neste sentido, percebe-se que o índice considera aspectos ambientais, sociais e econômicos.

A inclusão de uma empresa no ISE depende de alguns critérios cumulativos, a saber, a ação da empresa deve estar entre as 200 mais negociadas nas últimas três carteiras vigentes, deve estar presente em $50 \%$ dos pregões das últimas três carteiras, não ser classificada como "Penny Stock" (ativos cuja cotação seja inferior a $\mathrm{R} \$ 1,00$ ) e, por fim, deve atender aos critérios de sustentabilidade e ser selecionada pelo Conselho Deliberativo do ISE (BM\&F BOVESPA, 2016). Em relação à exclusão, as empresas terão suas ações excluídas do índice se deixarem de atender qualquer um dos critérios de inclusão acima listado, se a empresa que participa do índice sofrer intervenção, pedir recuperação judicial ou extrajudicial ou entrar em regime especial de administração temporária, e por fim, se o Conselho de Deliberação do ISE entender que o desempenho sustentável da empresa foi alterado em função de algum acontecimento ocorrido durante a vigência da carteira (BM\&F BOVESPA, 2016).

Flores et al. (2013) entendem que o ISE pode representar um diferencial para as empresas que dele participam, porque como se trata de um índice que exige dos participantes práticas ambientais sustentáveis, para os investidores, a presença da empresa no índice demonstra que a organização construiu uma boa imagem junto ao mercado. Os autores afirmam que as empresas demonstram ser vantajoso participar de um índice comprometido com a responsabilidade social e a sustentabilidade empresarial. Na perspectiva de Dias e Barros (2008), as práticas sustentáveis em várias dimensões exigidas das empresas, para fazerem parte do ISE, requerem das organizações mudanças na gestão, que podem variar de complexidade, de acordo com o segmento de atuação desta.

A metodologia adotada pelo Centro de Estudos em Sustentabilidade da FGV (GVces) para a seleção das empresas que participarão da carteira do ISE consiste na aplicação de um questionário, apenas com questões objetivas, destinado as 200 empresas com ações mais negociadas na BM\&F BOVESPA, que respondem de forma voluntária. Dessa forma, é possível notar o comprometimento da organização com práticas sustentáveis, que são cada vez mais cobradas pela sociedade e, particularmente, pelos investidores (BM\&F BOVESPA, 2016). Depois de enviadas as repostas, as empresas devem enviar documentos que comprovem as respostas dadas. Com isso, as respostas das companhias geram seu desempenho quantitativo, enquanto a documentação enviada gera o seu desempenho qualitativo. Com base nesses dois parâmetros é que o Conselho Deliberativo do ISE escolherá as empresas que participarão da carteira.

Revista Ambiente Contábil - ISSN 2176-9036 - UFRN - Natal-RN. v. 10. n. 1, p. 104 - 120, jan./jun. 2018. 
Mário de Carvalho Filho, Márcio Sampaio Pimentel, Rafaela Maria José Bertino e Anália Regina de Lima Oliveira

É oportuno explicar que o questionário considera o desempenho das empresas em sete dimensões: geral, natureza do produto, governança corporativa, mudanças climáticas, social, econômico-financeira e ambiental. Cada uma destas dimensões é dividida em critérios e estes, por sua vez, em indicadores. Critérios como política (indicadores de comprometimento), gestão (indicadores de programas, metas e monitoramento), desempenho, cumprimento legal dimensão ambiental, fazem parte, dentre outras. Um aspecto relevante da dimensão ambiental se refere a uma diferenciação dos questionários em função das atividades da empresa e de suas diferentes consequências no meio ambiente (BM\&F BOVESPA, 2016).

Essa metodologia adotada para a escolha das empresas que participarão do índice, utilizando-se de atributos quantitativos e qualitativos, exige das instituições que se propõem a compô-lo um grau de transparência maior do que o de outras empresas. Neste sentido, o nível de evidenciação ambiental das organizações participantes do ISE pode ser considerado acima da média do mercado. Silva et al. (2013), ao buscarem analisar as informações de gestão ambiental mais evidenciadas nos relatórios de administração e notas explicativas das empresas que compõem o ISE, entenderam que se deve esperar uma maior explicitação das informações ambientais nessas organizações, haja vista que o aspecto fundamental para compor esta carteira é exatamente a relação da empresa com o meio ambiente.

\section{ASPECTOS METODOLÓGICOS}

\subsection{CARACTERIZAÇÃO DA PESQUISA}

Essa investigação se define como "quantitativa", na medida em que consideramos a natureza dos dados analisados. Vieira (2010, p. 107) aponta que "as pesquisas quantitativas são aquelas que se propõem a explicar, por meio de dados quantificáveis, as causas, as consequências e as inter-relações entre fenômenos". Para este autor, a pesquisa quantitativa busca comprovar ou negar uma hipótese assumida no delineamento do trabalho por meio da coleta de dados, com a finalidade de descobrir padrões e tendências capazes de confirmar ou negar essa hipótese. Silva e Menezes (2001) afirmam que a pesquisa quantitativa traduz em números opiniões e informações para classificá-las e analisá-las. Trata-se de um objeto de investigação essencialmente descritivo, respeitando a lógica indutiva.

Segundo Prodanov e De Freitas (2013), nas pesquisas descritivas, observam-se, registram-se, analisam-se e organizam-se os dados, sem qualquer manipulação do investigador. No que tange à lógica indutiva, Marconi e Lakatos (2003, p.86) afirmam que "o objetivo dos argumentos indutivos é levar a conclusões cujo conteúdo é muito mais amplo do que o das premissas nas quais se basearam"

Nesse estudo se optou pela pesquisa documental. Gil (1999) afirma que, no âmbito da pesquisa documental, é possível identificar dois tipos de documentos os de primeira mão, que não receberam nenhum tratamento, e os de segunda mão, que já passaram por algum tipo de tratamento analítico (GIL, 1999).

\subsection{AMOSTRA E FORMA DE COLETA DOS DADOS}

A amostra analisada foi composta pelas empresas que disponibilizaram as suas respostas ao questionário aplicado pelo ISE (Índice de Sustentabilidade Empresarial) da BM\&F BOVESPA. Este questionário foi estruturado em sete dimensões, trinta critérios e setenta indicadores. Para esta pesquisa, foram utilizadas as repostas ao indicador 14, que 
Mário de Carvalho Filho, Márcio Sampaio Pimentel, Rafaela Maria José Bertino e Anália Regina de Lima Oliveira

corresponde a passivos ambientais - que faz parte do critério cumprimento legal na dimensão ambiental.

Foram coletadas todas as repostas que as empresas autorizaram a divulgação ao público nas carteiras de 2012, 2013, 2014 e 2015. Apesar da carteira de 2016 estar disponível no site da BM\&F BOVESPA, esta não foi utilizada, pois o formato das opções de resposta foi modificado, impossibilitando a comparação com os outros anos. É oportuno destacar que o questionário aplicado nos anos de 2012 e 2013 possuía sete alternativas de respostas, enquanto o questionário aplicado durante os anos de 2014 e 2015 possuía oito alternativas de respostas, com a inclusão da alternativa $\mathrm{H}$, que foi escolhida como resposta por apenas uma empresa, em todo o período analisado. Entretanto, este fato não impede a análise, uma vez que os textos das respostas não se alteram, apenas ocorrendo uma mudança de posição nas alternativas.

O Quadro 01, que corresponde ao indicador 14 do ISE, mostra a indagação feita às empresas em relação a seus passivos ambientais e também as opções de respostas que poderiam ter sido dadas.

\section{Quadro 01: Questionário utilizado como referência pela BOVESPA}

\begin{tabular}{|ll|}
\hline Qual a situação da companhia em relação a eventuais passivos ambientais? \\
\hline a) Não possui procedimento sistemático de avaliação e monitoramento de passivos ambientais. \\
\hline b) & $\begin{array}{l}\text { Avalia e monitora sistematicamente potenciais passivos ambientais e pode garantir que não possui } \\
\text { passivo ambiental. }\end{array}$ \\
\hline c) & Possui passivos ambientais, mas não provisionou recursos para o seu saneamento. \\
\hline d) & $\begin{array}{l}\text { Possui passivos ambientais, provisionou recursos para o seu saneamento, mas não divulga a } \\
\text { existência dos passivos nos relatórios pertinentes. }\end{array}$ \\
\hline e) & $\begin{array}{l}\text { Possui passivos ambientais, provisionou recursos para o seu saneamento e divulga a existência dos } \\
\text { passivos nos relatórios pertinentes (Deliberação CVM 594/2009). }\end{array}$ \\
\hline f) & $\begin{array}{l}\text { Possui passivos ambientais, provisionou recursos para o seu saneamento e divulga a existência dos } \\
\text { passivos nos relatórios pertinentes (Deliberação CVM 594/2009) e tem como meta o saneamento } \\
\text { integral dos passivos em prazo inferior a 10 anos. }\end{array}$ \\
g) Possui passivos ambientais, provisionou recursos para o seu saneamento e divulga a existência dos \\
passivos nos relatórios pertinentes (Deliberação CVM 594/2009) e tem como meta o saneamento \\
integral dos passivos em prazo inferior a 5 anos. \\
h) $\begin{array}{l}\text { Possui passivos ambientais, provisionou recursos para o seu saneamento e divulga a existência dos } \\
\text { passivos nos relatórios pertinentes (Deliberação CVM 594/2009) e tem como meta o saneamento } \\
\text { integral dos passivos em prazo inferior a 3anos. }\end{array}$ \\
\hline
\end{tabular}

Fonte: elaborado pelos autores (2017)

As respostas das empresas foram colhidas no site da BM\&F BOVESPA nos anos de 2012 a 2015. Além da reposta, também foi coletado o nome da companhia. Em relação às instituições financeiras, estas foram retiradas da amostra, pois pertencem ao grupo IF. Para esse grupo, em relação ao passivo ambiental, o ISE declara como reposta "não se aplica N/A". A sigla N/P (no quadro 2) indica que a empresa não participava do índice naquele ano.

Outro aspecto relevante a esclarecer está relacionado com a possibilidade de o número de respostas ao questionário ultrapassar o número máximo de companhias na carteira, 40 empresas. Isto pode ocorrer por que existem empresas que fazem parte de uma holding. Desta forma, cada empresa do grupo empresarial deve responder ao seu questionário. 
Mário de Carvalho Filho, Márcio Sampaio Pimentel, Rafaela Maria José Bertino e Anália Regina de Lima Oliveira

Quadro 2: Respostas das empresas em 2012, 2013, 2014 e 2015

\begin{tabular}{|c|c|c|c|c|}
\hline EMPRESAS & $\begin{array}{l}\text { REPOSTAS } \\
2012\end{array}$ & $\begin{array}{l}\text { RESPOSTAS } \\
2013\end{array}$ & $\begin{array}{l}\text { RESPOSTAS } \\
2014\end{array}$ & $\begin{array}{l}\text { RESPOSTA } \\
2015\end{array}$ \\
\hline AES TIETE S.A. & $\mathrm{G}$ & B & $\mathrm{E}$ & B \\
\hline $\begin{array}{c}\text { B2W- COMPANHIA } \\
\text { DIGITAL }\end{array}$ & $\mathrm{N} / \mathrm{P}$ & $\mathrm{N} / \mathrm{P}$ & $\mathrm{N} / \mathrm{P}$ & B \\
\hline BRASKEM S.A & $\mathrm{N} / \mathrm{P}$ & $\mathrm{N} / \mathrm{P}$ & N/P & $\mathrm{E}$ \\
\hline BRF S.A & $\mathrm{N} / \mathrm{P}$ & $\mathrm{N} / \mathrm{P}$ & $\mathrm{N} / \mathrm{P}$ & $\mathrm{F}$ \\
\hline $\begin{array}{l}\text { CONCESSIONÁRIA } \\
\text { PRES. DUTRA S/A }\end{array}$ & $\mathrm{D}$ & B & B & B \\
\hline $\begin{array}{l}\text { CONCESSIONÁRIA DE } \\
\text { ROD. DO OESTE DE SP- } \\
\text { VIA OESTE S/A }\end{array}$ & $\mathrm{D}$ & $\mathrm{E}$ & B & B \\
\hline $\begin{array}{l}\text { CONCESSIONÁRIA DO } \\
\text { SISTEMA } \\
\text { ANHANGUERA- } \\
\text { BANDEIRANTES S/A }\end{array}$ & $\mathrm{D}$ & G & B & B \\
\hline $\begin{array}{l}\text { RODONORTE- } \\
\text { CONCESSIONÁRIA DE } \\
\text { ROD. INTEGRADAS S/A }\end{array}$ & $\mathrm{D}$ & B & B & B \\
\hline $\begin{array}{l}\text { RODOVIAS } \\
\text { INTEGRADAS DO } \\
\text { OESTE S.A } \\
\end{array}$ & $\mathrm{N} / \mathrm{P}$ & $\mathrm{E}$ & $\mathrm{D}$ & B \\
\hline $\begin{array}{l}\text { CEMIG GERAÇÃO E } \\
\text { TRANSMISSÃO S.A }\end{array}$ & $\mathrm{N} / \mathrm{P}$ & D & B & B \\
\hline $\begin{array}{l}\text { CEMIG DISTRIBUIÇÃO } \\
\text { S.A }\end{array}$ & $\mathrm{N} / \mathrm{P}$ & B & B & B \\
\hline CIELO S.A & $\mathrm{N} / \mathrm{P}$ & $\mathrm{N} / \mathrm{P}$ & $\mathrm{B}$ & $\mathrm{B}$ \\
\hline $\begin{array}{l}\text { CPFL GERAÇÃO DE } \\
\text { ENERGIA S.A }\end{array}$ & $\mathrm{N} / \mathrm{P}$ & $\mathrm{N} / \mathrm{P}$ & $\mathrm{N} / \mathrm{P}$ & B \\
\hline $\begin{array}{l}\text { COMPANHIA } \\
\text { PAULISTA DE FORÇA E } \\
\text { LUZ }\end{array}$ & $\mathrm{N} / \mathrm{P}$ & $\mathrm{N} / \mathrm{P}$ & N/P & B \\
\hline $\begin{array}{l}\text { COMPANHIA } \\
\text { PIRATININGA DE } \\
\text { FORÇA E LUZ } \\
\end{array}$ & $\mathrm{N} / \mathrm{P}$ & $\mathrm{N} / \mathrm{P}$ & N/P & B \\
\hline $\begin{array}{l}\text { RIO GRANDE ENERGIA } \\
\text { S.A }\end{array}$ & $\mathrm{N} / \mathrm{P}$ & $\mathrm{N} / \mathrm{P}$ & $\mathrm{N} / \mathrm{P}$ & B \\
\hline $\begin{array}{l}\text { CIA ENERG. DO } \\
\text { CEARA- COELCE }\end{array}$ & B & B & B & B \\
\hline $\begin{array}{l}\text { CIA SANEAMENTO DE } \\
\text { MINAS GERAIS- } \\
\text { COPASA MG }\end{array}$ & $\mathrm{N} / \mathrm{P}$ & $\mathrm{N} / \mathrm{P}$ & D & $\mathrm{N} / \mathrm{P}$ \\
\hline $\begin{array}{l}\text { COPEL DISTRIBUIÇÃO } \\
\text { S.A }\end{array}$ & $\mathrm{N} / \mathrm{P}$ & $\mathrm{N} / \mathrm{P}$ & $\mathrm{E}$ & $\mathrm{E}$ \\
\hline $\begin{array}{l}\text { COPEL GERAÇÃO E } \\
\text { TRANSMISSÃO S.A }\end{array}$ & $\mathrm{N} / \mathrm{P}$ & $\mathrm{N} / \mathrm{P}$ & $\mathrm{E}$ & $\mathrm{E}$ \\
\hline DURATEX S.A & $\mathrm{N} / \mathrm{P}$ & $\mathrm{N} / \mathrm{P}$ & B & A \\
\hline $\begin{array}{l}\text { CONC. DAS ROD. } \\
\text { AYRTON SENNA E C. } \\
\text { PINTO S.A- ECOPISTAS }\end{array}$ & $\mathrm{N} / \mathrm{P}$ & $\mathrm{N} / \mathrm{P}$ & $\mathrm{N} / \mathrm{P}$ & G \\
\hline $\begin{array}{l}\text { CONC. ECOVIA } \\
\text { CAMINHO DO MAR S.A }\end{array}$ & N/P & $\mathrm{N} / \mathrm{P}$ & $\mathrm{N} / \mathrm{P}$ & $\mathrm{F}$ \\
\hline CONC. ECOVIAS DOS & & & & $\mathrm{G}$ \\
\hline
\end{tabular}

Revista Ambiente Contábil - ISSN 2176-9036 - UFRN - Natal-RN. v. 10. n. 1, p. 104 - 120, jan./jun. 2018 
Mário de Carvalho Filho, Márcio Sampaio Pimentel, Rafaela Maria José Bertino e Anália Regina de Lima Oliveira

\begin{tabular}{|c|c|c|c|c|}
\hline IMIGRANTES S.A & $\mathrm{N} / \mathrm{P}$ & $\mathrm{N} / \mathrm{P}$ & $\mathrm{N} / \mathrm{P}$ & \\
\hline $\begin{array}{l}\text { ECOPORTO SANTOS } \\
\text { S.A }\end{array}$ & $\mathrm{N} / \mathrm{P}$ & $\mathrm{N} / \mathrm{P}$ & $\mathrm{N} / \mathrm{P}$ & $\mathrm{D}$ \\
\hline $\begin{array}{l}\text { EMPRESA CONC. DE } \\
\text { RODOVIAS DO SUL } \\
\text { S.A- ECOSUL }\end{array}$ & $\mathrm{N} / \mathrm{P}$ & $\mathrm{N} / \mathrm{P}$ & $\mathrm{N} / \mathrm{P}$ & $\mathrm{B}$ \\
\hline $\begin{array}{l}\text { RODOVIA DAS } \\
\text { CATARATAS S.A- } \\
\text { ECOCATARATAS }\end{array}$ & $\mathrm{N} / \mathrm{P}$ & $\mathrm{N} / \mathrm{P}$ & $\mathrm{N} / \mathrm{P}$ & B \\
\hline $\begin{array}{l}\text { CHESF- COMPANHIA } \\
\text { HIDRO ELETRICA DO } \\
\text { SÃO FRANCISCO }\end{array}$ & $\mathrm{N} / \mathrm{P}$ & A & A & $\mathrm{C}$ \\
\hline $\begin{array}{l}\text { CENTRAIS ELETRICAS } \\
\text { DO NORTE DO BRASIL } \\
\text { S.A }\end{array}$ & $\mathrm{N} / \mathrm{P}$ & $\mathrm{C}$ & $\mathrm{C}$ & $\mathrm{D}$ \\
\hline ITAIPU BINACIONAL & $\mathrm{N} / \mathrm{P}$ & $\mathrm{B}$ & $\mathrm{B}$ & $\mathrm{B}$ \\
\hline $\begin{array}{l}\text { CIA DE GERAÇÃO } \\
\text { TERMICA DE ENERGIA } \\
\text { ELETRICA }\end{array}$ & $\mathrm{N} / \mathrm{P}$ & B & $\mathrm{B}$ & B \\
\hline $\begin{array}{l}\text { ELETROBRAS } \\
\text { TERMONUCLEAR S.A }\end{array}$ & $\mathrm{N} / \mathrm{P}$ & $\mathrm{D}$ & $\mathrm{E}$ & $\mathrm{E}$ \\
\hline $\begin{array}{l}\text { COMPANHIA } \\
\text { ENERGETICA DO PIAUI }\end{array}$ & $\mathrm{N} / \mathrm{P}$ & $\mathrm{C}$ & B & $\mathrm{B}$ \\
\hline $\begin{array}{l}\text { AMAZONAS DIST. DE } \\
\text { ENERGIA S.A }\end{array}$ & $\mathrm{N} / \mathrm{P}$ & $\mathrm{C}$ & $\mathrm{E}$ & $\mathrm{E}$ \\
\hline $\begin{array}{l}\text { FURNAS CENTRAIS } \\
\text { ELETRICAS S.A }\end{array}$ & $\mathrm{N} / \mathrm{P}$ & $\mathrm{D}$ & $\mathrm{E}$ & $\mathrm{E}$ \\
\hline $\begin{array}{l}\text { ELETROSUL CENTRAS } \\
\text { ELETRICAS S.A }\end{array}$ & $\mathrm{N} / \mathrm{P}$ & $\mathrm{C}$ & $\mathrm{C}$ & $\mathrm{D}$ \\
\hline $\begin{array}{l}\text { CENTRAIS ELETRICAS } \\
\text { DE RONDONIA S.A }\end{array}$ & $\mathrm{N} / \mathrm{P}$ & $\mathrm{N} / \mathrm{P}$ & $\mathrm{C}$ & $\mathrm{C}$ \\
\hline $\begin{array}{l}\text { COMPANHIA } \\
\text { ENERGETICA DE } \\
\text { ALAGOAS }\end{array}$ & $\mathrm{N} / \mathrm{P}$ & $\mathrm{N} / \mathrm{P}$ & $\mathrm{C}$ & $\mathrm{C}$ \\
\hline $\begin{array}{l}\text { COMPANHIA DE } \\
\text { ELETRECIDADE DO } \\
\text { ACRE }\end{array}$ & $\mathrm{N} / \mathrm{P}$ & $\mathrm{N} / \mathrm{P}$ & A & A \\
\hline $\begin{array}{l}\text { ELETROPAULO } \\
\text { METROP. ELET. SÃO } \\
\text { PAULO S.A. }\end{array}$ & $\mathrm{D}$ & $\mathrm{D}$ & $\mathrm{E}$ & $\mathrm{E}$ \\
\hline $\begin{array}{l}\text { BANDEIRANTE } \\
\text { ENERGIA S.A. }\end{array}$ & $\mathrm{F}$ & $\mathrm{C}$ & $\mathrm{C}$ & $\mathrm{D}$ \\
\hline $\begin{array}{l}\text { ESPÍRITO SANTO } \\
\text { CENTRAIS ELÉTRICAS } \\
\text { S.A. }\end{array}$ & $\mathrm{C}$ & $\mathrm{C}$ & $\mathrm{C}$ & $\mathrm{C}$ \\
\hline $\begin{array}{l}\text { EDP- } \\
\text { COMERCIALIZAÇÃO E } \\
\text { SERVIÇOS DE } \\
\text { ENERGIA LTDA. }\end{array}$ & $\mathrm{N} / \mathrm{P}$ & $\mathrm{N} / \mathrm{P}$ & $\mathrm{N} / \mathrm{P}$ & $\mathrm{B}$ \\
\hline ENERPEIXE S.A & $\mathrm{N} / \mathrm{P}$ & $\mathrm{B}$ & $\mathrm{B}$ & $\mathrm{N} / \mathrm{P}$ \\
\hline $\begin{array}{l}\text { ENGIE BRASIL } \\
\text { ENERGIA S.A }\end{array}$ & $\mathrm{N} / \mathrm{P}$ & $\mathrm{N} / \mathrm{P}$ & $\mathrm{N} / \mathrm{P}$ & $\bar{E}$ \\
\hline $\begin{array}{l}\text { EVEN CONSTRUTORA } \\
\text { E INCORPORADORA } \\
\text { S.A }\end{array}$ & $\mathrm{N} / \mathrm{P}$ & $\mathrm{N} / \mathrm{P}$ & B & B \\
\hline FIBRIA CELULOSE S.A & $\mathrm{N} / \mathrm{P}$ & $\mathrm{N} / \mathrm{P}$ & $\mathrm{N} / \mathrm{P}$ & $E$ \\
\hline FLEURY S.A & $\mathrm{N} / \mathrm{P}$ & $\mathrm{N} / \mathrm{P}$ & $\mathrm{N} / \mathrm{P}$ & $\mathrm{B}$ \\
\hline
\end{tabular}

Revista Ambiente Contábil - ISSN 2176-9036 - UFRN - Natal-RN. v. 10. n. 1, p. 104 - 120, jan./jun. 2018. 
Mário de Carvalho Filho, Márcio Sampaio Pimentel, Rafaela Maria José Bertino e Anália Regina de Lima Oliveira

\begin{tabular}{|l|c|c|c|c|}
\hline JSL S.A & N/P & N/P & N/P & D \\
\hline $\begin{array}{l}\text { JSL INVEST. EM CONC. } \\
\begin{array}{l}\text { E LOJAS DE VEÍC. } \\
\text { MAQ. E EQUIP. S.A }\end{array}\end{array}$ & $\mathrm{N} / \mathrm{P}$ & $\mathrm{N} / \mathrm{P}$ & $\mathrm{N} / \mathrm{P}$ & $\mathrm{C}$ \\
\hline KLABIN S.A & $\mathrm{N} / \mathrm{P}$ & $\mathrm{N} / \mathrm{P}$ & $\mathrm{H}$ & $\mathrm{B}$ \\
\hline $\begin{array}{l}\text { LIGHT SERVIÇOS } \\
\text { ELETRECIDADE S.A }\end{array}$ & $\mathrm{N} / \mathrm{P}$ & $\mathrm{C}$ & $\mathrm{C}$ & $\mathrm{B}$ \\
\hline $\begin{array}{l}\text { LOJAS AMERICANAS } \\
\text { S.A }\end{array}$ & $\mathrm{N} / \mathrm{P}$ & $\mathrm{N} / \mathrm{P}$ & $\mathrm{N} / \mathrm{P}$ & $\mathrm{B}$ \\
\hline LOJAS RENNER S.A & $\mathrm{N} / \mathrm{P}$ & $\mathrm{N} / \mathrm{P}$ & $\mathrm{N} / \mathrm{P}$ & $\mathrm{B}$ \\
\hline $\begin{array}{l}\text { NATURA COSMÉTICOS } \\
\text { S.A. }\end{array}$ & $\mathrm{B}$ & $\mathrm{B}$ & $\mathrm{B}$ & $\mathrm{B}$ \\
\hline VALE S.A & $\mathrm{N} / \mathrm{P}$ & $\mathrm{E}$ & $\mathrm{E}$ & $\mathrm{E}$ \\
\hline $\begin{array}{l}\text { VALE FERTILIZANTES } \\
\text { S.A }\end{array}$ & $\mathrm{N} / \mathrm{P}$ & $\mathrm{E}$ & $\mathrm{E}$ & $\mathrm{F}$ \\
\hline WEG S.A & $\mathrm{N} / \mathrm{P}$ & $\mathrm{B}$ & $\mathrm{B}$ & $\mathrm{B}$ \\
\hline
\end{tabular}

Fonte: elaborado pelos autores (2017).

\section{ANÁLISE DOS RESULTADOS}

A análise proposta nesta pesquisa trata do percentual de escolha de cada alternativa dentre aquelas constantes do Quadro 1. Isto representa um aspecto importante para os stakedolders interessados nestas organizações. Estas respostas representam o nível de comprometimento das empresas com o meio ambiente, pois a partir delas, pode-se entender como as organizações se relacionam com o meio onde estão inseridas. $\mathrm{O}$ gráfico 1 , disposto abaixo, resume os quatro anos analisados, além de mostrar que $81 \%$ das alternativas escolhidas pelas empresas se dividem em três: a alternativa B (43\%), a alternativa E (22\%) e a alternativa C (16\%). É oportuno destacar que a alternativa B obteve quase o dobro do percentual da segunda colocada, a alternativa $\mathrm{E}$.

\section{Gráfico 1- Percentual de resposta por alternativa do Quadro 1 no período de 2012-2015}

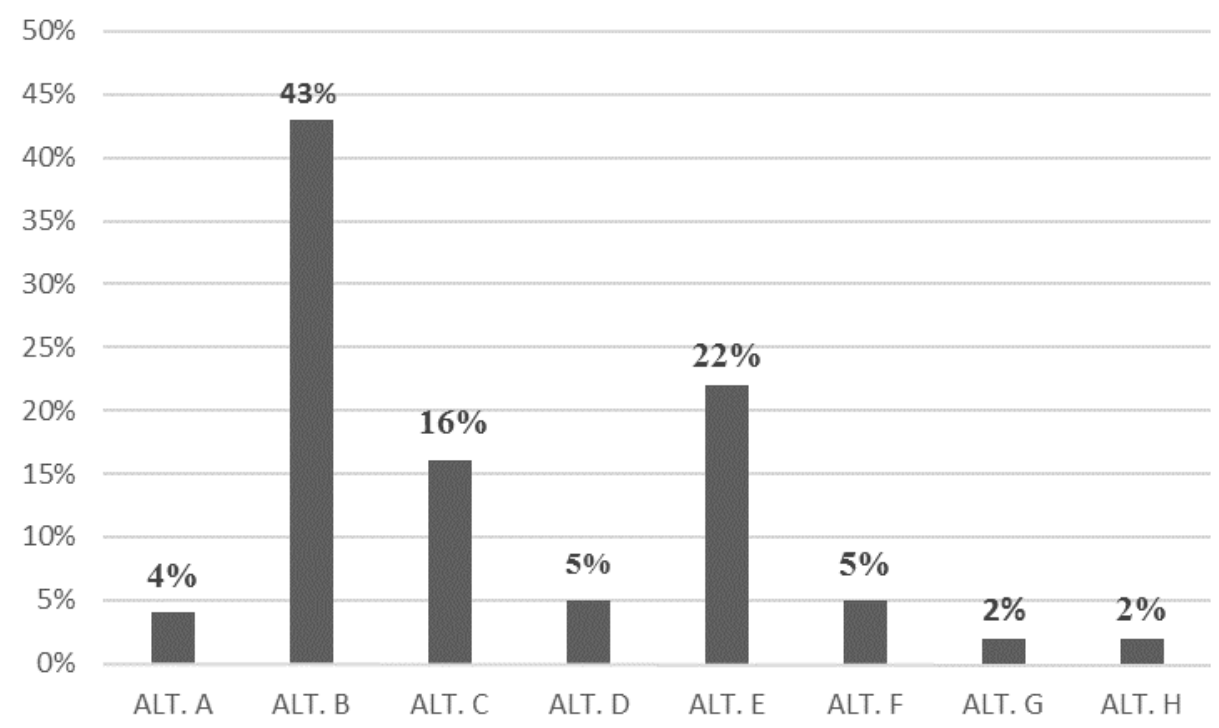

Fonte: elaborado pelos autores.

Revista Ambiente Contábil - ISSN 2176-9036 - UFRN - Natal-RN. v. 10. n. 1, p. 104 - 120, jan./jun. 2018. 
Mário de Carvalho Filho, Márcio Sampaio Pimentel, Rafaela Maria José Bertino e Anália Regina de Lima Oliveira

A alternativa B afirma que a empresa avalia e monitora sistematicamente potenciais passivos ambientais e pode garantir que não possui passivo ambiental. Uma das exigências para que a empresa seja aceita no índice é a comprovação por meio de documentos das respostas dadas. No entanto, estes documentos não são disponibilizados no site da $\mathrm{BM} \& \mathrm{~F}$ BOVESPA para que o investidor possa ter acesso a esta informação. Desta forma, tem-se que 43\% das empresas que responderam ao questionário nos anos 2012, 2013, 2014 e 2015 declararam não possuir passivos ambientais - comprovados através de documentos que somente a BM\&F BOVESPA teve acesso. Esta alternativa de resposta se mostra relevante para aqueles interessados em adquirir uma destas empresas, já que Bertoli e Ribeiro (2006) afirmaram que uma descoberta posterior à compra de passivos ambientais não evidenciados nos demonstrativos da empresa pode gerar pedidos de pagamentos de multas na esfera judicial ou, até mesmo, o cancelamento do negócio.

$\mathrm{Na}$ alternativa $\mathrm{E}$, a empresa declara que possui passivo ambiental, que provisiona recursos para o seu saneamento e divulga a existência dos passivos nos relatórios pertinentes. Esta opção foi escolhida por $22 \%$ das empresas participantes do ISE no recorte temporal dessa investigação. A alternativa $\mathrm{E}$ como resposta pode ser importante, por exemplo, para investidores, que procuram empresas com maior grau de comprometimento ambiental para investirem o seu dinheiro e auferirem maiores lucros.

A terceira opção de resposta mais escolhida pelas empresas participantes do ISE foi a alternativa C. Durante os anos do quadriênio 2012-2015, esta opção foi escolhida por 16\% das companhias. A empresa que escolhe esta opção declara que possui passivos ambientais, mas não provisionou recursos para o seu saneamento. Órgãos de fiscalização, em tese, compreendem os usuários mais interessados nesta opção de resposta, pois, a instituição que reconhece a existência de passivos ambientais - mas não provisiona recursos para o seu saneamento - apresenta um resultado financeiro inflacionado. Assim, os órgãos de fiscalização atuariam na defesa de outros usuários, possivelmente, prejudicados pelas demonstrações financeiras incompletas.

Com valores menos expressivos as alternativas $\mathrm{D}$ e $\mathrm{F}$ foram escolhidas por $5 \%$ das companhias pertencentes ao ISE no recorte temporal em tela. As empresas que escolhem a alternativa $\mathrm{D}$ informaram que possuem passivos ambientais, provisionaram recursos para o seu saneamento, mas não divulgaram a existência dos passivos ambientais nos relatórios pertinentes. Os investidores podem ser os mais interessados nesta alternativa de resposta. Já que podem ser prejudicados ao efetuarem uma análise superficial nos relatórios das empresas, por não possuírem conhecimentos contábeis para analisar um balanço patrimonial e identificarem os passivos ambientais ali evidenciados.

Já as empresas que optaram pela alternativa $\mathrm{F}$, por sua vez, declararam possuir passivos ambientais, provisionaram recursos para o seu saneamento e divulgaram a existência dos passivos nos relatórios pertinentes, além disso, possuem como meta o saneamento integral dos passivos em um prazo inferior a dez anos. As alternativas G (2\%) e H (2\%) também possuem textos muito semelhantes àquele da alternativa $\mathrm{F}$. O que as diferencia, no entanto, é o prazo para o saneamento integral dos passivos, na alternativa $\mathrm{G}$, o prazo é de cinco anos e na alternativa $\mathrm{H}$, três anos. Estas respostas demonstram o comprometimento das empresas com práticas sustentáveis, cada vez mais cobradas pela sociedade e, particularmente, pelos investidores (BM\&F BOVESPA, 2016).

Por fim, a alternativa A foi escolhida por $4 \%$ das empresas que participaram do ISE nos anos de 2012 a 2015. As empresas que escolheram esta alternativa declararam não possuir procedimento sistemático de avaliação e monitoramento de passivos ambientais. Esta resposta demonstra que a empresa não adota práticas ambientais sustentáveis, mas participa de um

Revista Ambiente Contábil - ISSN 2176-9036 - UFRN - Natal-RN. v. 10. n. 1, p. 104 - 120, jan./jun. 2018. 
Mário de Carvalho Filho, Márcio Sampaio Pimentel, Rafaela Maria José Bertino e Anália Regina de Lima Oliveira

índice cujo diferencial é a boa relação da organização com o meio ambiente. De acordo com Flores et al. (2013) as empresas que participam do ISE possuem uma boa imagem junto ao mercado, já que se trata de um índice que exige boas práticas ambientais.

\section{CONSIDERAÇÕES FINAIS}

O Índice de Sustentabilidade Empresarial (ISE) da BM\&F BOVESPA é uma ferramenta que permite comparar o desempenho das empresas com ações no mercado de capitais, especificamente no atributo da sustentabilidade corporativa. Além disso, o ISE amplia a compreensão das companhias em relação ao nível de compromisso com o desenvolvimento sustentável, transparência na prestação de contas e o desempenho empresarial nas dimensões econômico-financeira, social, ambiental e de mudanças climáticas. Sendo, desta forma, relevante para vários atores interessados nas empresas que dele participam como por exemplo, a sociedade, o governo, os investidores, e as próprias empresas.

Portanto, o objetivo principal desta pesquisa concentrou-se em descrever como as empresas participantes do ISE da BM\&F BOVESPA se auto declararam em relação a seus passivos ambientais nos anos de 2012, 2013, 2014 e 2015. Na visão de Murcia et al. (2008) deve-se esperar mais evidenciação ambiental das empresas que participam do ISE, uma vez que a carteira representa o comprometimento das companhias com a responsabilidade social e a sustentabilidade.

Os resultados demonstraram que as empresas integrantes do ISE possuem um baixo nível de evidenciação de seus passivos ambientais, já que $43 \%$ das empresas garantiram não possuir passivos ambientais e 16\% afirmaram possuir passivos ambientais, mas não provisionam recursos para saneá-los, esses dados representam 59\% da amostra analisada. As implicações deste baixo nível de evidenciação ambiental podem afetar às empresas causando a perda de confiabilidade junto aos consumidores e, até mesmo, diminuição de valor de mercado. Para os investidores, o baixo nível de evidenciação prejudica a análise com vistas ao investimento, já que as demonstrações contábeis não serão suficientemente claras em relação à existência de passivos ambientais. Estes são apenas dois exemplos de atores prejudicados pela baixa evidenciação ambiental, todavia, este trabalho deixou claro que existem vários outros interessados que podem ser prejudicados por esta falta de transparência.

A contribuição desta pesquisa consiste em revelar para os diversos interessados nas empresas que compõem o ISE como estas se declararam acerca de seus passivos ambientais. O trabalho revelou como cada uma respondeu ao ser questionada sobre seus passivos ambientais e, de acordo com os resultados encontrados, ficou evidente que a simples presença de uma organização em um índice de sustentabilidade empresarial não garante que esta evidencie de maneira transparente os seus passivos ambientais. Isto contraria Silva et al. (2013), que entenderam que, se deve esperar das empresas que compõem o ISE uma maior explicitação de seus passivos ambientais.

Assim, o presente estudo procura auxiliar os investidores, os usuários das demonstrações financeiras e a sociedade em geral na tomada de decisão, fornecendo informações acerca do nível de evidenciação dos passivos ambientais nas empresas que compõem o ISE da BM\&F BOVESPA. Na visão de Flores et al. (2013), para os investidores, a presença da empresa no índice demonstra que a organização construiu uma boa imagem junto ao mercado.

Como pesquisas posteriores, sugere-se, além da análise nas respostas ao questionário de seleção do ISE, um exame nas demonstrações contábeis, incluindo relatórios da

Revista Ambiente Contábil - ISSN 2176-9036 - UFRN - Natal-RN. v. 10. n. 1, p. 104 - 120, jan./jun. 2018. 
Mário de Carvalho Filho, Márcio Sampaio Pimentel, Rafaela Maria José Bertino e Anália Regina de Lima Oliveira

administração e notas explicativas, na tentativa de comparar o nível de evidenciação declarado no questionário com o que consta nas demonstrações financeiras. Uma outra sugestão seria um levantamento acerca das metodologias de avaliação de passivos ambientais adotadas pelas empresas que fazem parte do ISE.

\section{REFERÊNCIAS}

ALMEIDA, K. K. N. de; BATISTA, F. F. Provisões contingentes ambientais e seus reflexos das empresas de alto impacto ambiental após adoção de CPC 25. Sociedade, Contabilidade e Gestão, Rio de Janeiro, v. 11, n.1, jan./abr. 2016.

BERTOLI, A. L.; RIBEIRO, M. de S. Passivo ambiental: estudo de caso da Petróleo Brasileiro S.A- Petrobrás. A repercussão ambiental nas demonstrações contábeis, em consequência dos acidentes ocorridos. RAC, v. 10, n. 2, abr./jun. 2006.

BEUREN, I. M. (org.). Como elaborar trabalhos monográficos em contabilidade: teoria e prática. São Paulo: Atlas, 2003.

BM\&FBOVESPA. ISE - Índice de Sustentabilidade Empresarial. Bolsa de Valores de São Paulo. Disponível em: http://www.bmfbovespa.com.br. Acesso em: 30 de novembro de 2016.

COSTA, R. S.; MARION, J. C. A uniformidade na evidenciação das informações ambientais. R. Cont. Fin. - USP. São Paulo, n. 43, p. 20-33, jan./Abr. 2007.

CPC- COMITÊ DE PRONUNCIAMENTOS CONTÁBEIS. Pronunciamento Técnico CPC 25: provisões, passivos contingentes e ativos contingentes, de 26 de junho de 2009. Disponível em: http://www.cpc.org.br/pdf/CPC_25.pdf. Acesso em 27 de setembro de 2016.

DIAS, E. A.; BARROS, L. A. Sustentabilidade empresarial e retorno ao acionista: um estudo sobre o ISE. In: Encontro da ANPAD, XXXII, 2008, Rio de Janeiro. Anais... Rio de Janeiro: ANPAD, 2008. CD-ROM.

FERNANDES, S. M. Os efeitos do disclosure ambiental negativo involuntário: um estudo de evento nas companhias brasileiras com alto índice de poluição. Revista de Contabilidade e Organizações, v. 17, p. 59-72, 2013.

FERNANDES, S. M. Fatores que influencias o disclosure ambiental: um estudo nas empresas brasileiras no período de 2006 a 2010. Revista Ambiente Contábil - UFRN, Natal-RN, v. 5, n. 2, p. 250-267, jul./dez. 2013 b.

FERREIRA, A. C.; BUFONI, A. L.; MUNIZ, N. P. Utilização do modelo isar/unctad: uma análise corporativa. Revista Pensar Contábil, Rio de Janeiro, v. 9, n. 35, p. 27-34, jan./mar. 2007.

FILHO, R. N. L.; BRUNI, A. L.; GOMES, S. M. S. A compreensão dos estudantes sobre o conceito de passivo ambiental: um estudo nos cursos de ciências contábeis em Salvador- BA. RPCA, Rio de Janeiro, v. 7, n.1, p. 108-121, jan./mar. 2013. 
Mário de Carvalho Filho, Márcio Sampaio Pimentel, Rafaela Maria José Bertino e Anália Regina de Lima Oliveira

FLORES, S. De A.; DEBONA, E. S.; BUENO, W. P.; ZUCATTO, L. C. Diagnóstico do índice de sustentabilidade empresarial. Salão do Conhecimento, v. 1, n. 1, 2013.

GIL, A. C. Métodos e Técnicas de pesquisa social. 5. ed. São Paulo: Atlas, 1999.

HAHN, A. V.; REZENDE, I. A. C.; NOSSA, V. O seguro ambiental como mecanismo de minimização do passivo ambiental das empresas. Revista Universo Contábil, Blumenau, v. 6, n. 2, p. 61-81, abr./jun. 2010.

JACOBS, B. W.; SINGHAL, V. R.; SUBRAMANIAN, R. An empirical investigation of environmental performance and market value of the firm. Journal of Operations Management, v. 28, p. 430-441, 2010.

KNOEPFEL, I. Dow Jones sustainability group index: a global benchmark for corporate sustainability. Corporate Environmental Strategy, v. 8, p. 6-15, 2001.

LINS, L. S.; SILVA, R. N. S. Responsabilidade Sócio-Ambiental ou Greenwash: uma avaliação com base nos relatórios de sustentabilidade ambiental. Sociedade, Contabilidade e Gestão, Rio de Janeiro, V. 4, n. 1, jan./jun. 2009.

MARCONI, M. A.; LAKATOS, E. M. Fundamentos de metodologia científica. 5. ed.-São Paulo: Atlas, 2003.

MIRANDA, W. B.; MALAQUIAS, R. F. Análise do nível de evidenciação ambiental de empresas brasileiras que negociam adrs na bolsa de valores de Nova Iorque (NYSE). Revista Ambiente Contábil - UFRN, Natal/RN, v. 5, n. 1, p. 93-111, jan./jun. 2013.

MURCIA, F. D.; ROVER, S.; LIMA, I.; FÁVERO, L. P. L.; LIMA, G. A. S. F. de. "Disclosure verde" nas demonstrações contábeis: características da informação ambiental e possíveis explicações para a divulgação voluntária. Revista UnB Contábil, v. 11, n. 1-2, p. 260-278, jan./dez. 2008.

NOGUEIRA, K. G. F.; ANGOTTI, M. Os efeitos da divulgação de impactos ambientais: um estudo de eventos em companhias petrolíferas. Revista Contemporânea de Contabilidade UFSC. Florianópolis, v. 8, n. 16, p. 65-88, jul./dez., 2011.

PRODANOV, C. C.; FREITAS, E. C. de. Metodologia do trabalho científico: métodos e técnicas da pesquisa e do trabalho acadêmico - 2. Ed. - Novo Hamburgo: Feevale, 2013.

RIBEIRO, M. S.; LISBOA, L. P. Passivo ambiental. Anais do Congresso Brasileiro de Contabilidade, Goiânia, GO, de 15 a 20 de outubro de 2000.

ROSA, F. S.; ENSSLIN, S. R.; ENSSLIN, L.; LUNKES, R. J. Gestão da evidenciação ambiental: um estudo sobre as potencialidades e oportunidades do tema. Eng Sanit Ambient, v. 16, n. 1, p. 157-166, jan./mar., 2011. 
Mário de Carvalho Filho, Márcio Sampaio Pimentel, Rafaela Maria José Bertino e Anália Regina de Lima Oliveira

ROVER, S.; TOMAZZIA, E. C.; MURCIA, F. D.; BORBA. Explicações para a divulgação voluntária ambiental no Brasil utilizando a análise de regressão em painel. R. Adm., v. 47, n. 2, o. 217-230, abr./maio/jun. 2012.

SILVA, E. L.; MENEZES, E. M. Metodologia da pesquisa e elaboração de dissertação. 3 ed. Florianópolis: Laboratório de Ensino à Distância da UFSC, 2001.

SILVA, J. O.; ROCHA, I.; WIENHAGE, P.; RAUSCH, R. B. Gestão ambiental: uma análise da evidenciação das empresas que compõem o índice de sustentabilidade empresarial (ISE). RGSA - Revista Gestão Social e Ambiental, v. 3, n. 3, p. 56-71, set./dez. 2009.

SPERANDIO, L. A.; TRINDADE, M.; FAVERO, H. L. Uma introdução à discussão do passivo ambiental. Reflexão Contábil, v. 24, n. 2, p. 05-18, jul./dez. 2005.

SUAVE, R.; CODESSO, M. M.; PINTO, H. M.; VICENTE, E. F. R.; LUNKES, R. J. Divulgação de passivos contingentes nas empresas mais líquidas da BM\&FBovespa. Revista da UNIFEBE, v. 1 n. 11, 2013.

TEIXEIRA, E. A.; NOSSA, V. FUNCHAL, B. O índice de sustentabilidade empresarial (ISE) e os impactos no endividamento e na percepção de risco. R. Cont. Fin. - USP. São Paulo, v. 22, n. 55, p.29-44, jan./fev./mar./abr. 2011.

VIEIRA, J. G. S. Metodologia de pesquisa científica na prática. Curitiba: Editora Fael, 2010. 